\title{
Multiple-organ failure as a result of non-COVID-19 coronavirus infection
}

\author{
José M. López Álvarez M.D. ${ }^{a, d}$, Joaquín Quiralte Castillo M.D. ${ }^{a}$, Olivia Pérez Quevedo M.D. ${ }^{a}$, \\ Jano Rubio García M.D. ${ }^{b}$, Carmen Pérez González M.D. ${ }^{c}$ and Dionisio L. Lorenzo Villegas M.D. ${ }^{d}$
}

\begin{abstract}
Coronavirus infections $(\mathrm{CoV})$ are common in pediatric patients. In general, they produce a mild clinical presentation consisting of an upper respiratory tract infection that does not usually infect the lungs, with the exception of preterm infants and children with chronic diseases. These infections exceptionally affect other organs (heart, brain, gastrointestinal tract), thus increasing their severity.

In relation to the temporal coincidence with the beginning of the current situation of pandemic by the new beta coronavirus SARS-CoV-2 responsible for its associated disease (COVID-19), this study presents a clinical case of a 5 -year-old patient showing multiple-organ failure and neurological sequelae due to bulbar injury and vascular thrombosis caused by an alpha coronavirus (CoV-NL63) due to its severity and exceptionality.

Key words: coronavirus infections non-COVID-19, multiple-organ failure, child.
\end{abstract}

http: / / dx.doi.org/10.5546/ aap.2021.eng.e252

To cite: López Álvarez JM, Quiralte Castillo J, Pérez Quevedo O, Rubio García J, et al. Multiple-organ failure as a result of non-COVID-19 coronavirus infection. Arch Argent Pediatr 2021;119(3):e252-e255.

\section{INTRODUCTION}

In pediatric patients, the respiratory viral infections by influenzae virus, adenovirus, rhinovirus, coronavirus (CoV) usually show limited clinical presentations. Exceptionally progress to a severe respiratory insufficiency with pulmonary involvement (bronchiolitis or respiratory distress syndrome), mainly in children with prematurity history or underlying chronic diseases. ${ }^{1,2}$

a. Unit of Paediatric Intensive Medicine. Mother and Child University Hospital of the Canary Islands. Spain.

b. Department of Radiology. Mother and Child University Hospital of the Canary Islands. Spain.

c. Department of Microbiology. Dr. Negrín Hospital of the Canary Islands. Spain.

d. Faculty of Health Sciences. Fernando Pessoa-Canarias University. Spain.

E-mail address:

José M. López Álvarez, M.D.: jmloal@hotmail.com

Funding: None.

Conflict of interest: None.

Received: 7-31-2020

Accepted: 11-11-2020
Extrapulmonary involvement secondary to $\mathrm{CoV}$ infection is less frequent ${ }^{2,3}$ and, mostly in more serious cases, it is derived from the primary pulmonary involvement.

In this study, a clinical case characterized by multiple-organ failure and neurological sequelae associated to isolation of CoV-NL63 in the nasopharyngeal wash collection in a 5-yearold patient is presented.

\section{Case presentation}

A 5-year-old child, on December 3 2019, showed an altered level of consciousness with alternating lethargy and irritability, in a 24-hourevolution context of $39^{\circ} \mathrm{C}$ fever, odynophagia and food vomiting.

The physical examination highlights the following: a) hearth rate: $60 \mathrm{bpm}$, blood pressure: $166 / 109 \mathrm{mmHg}$, breathing rate: $10 \mathrm{bpm}, \mathrm{SatO}_{2}$ : $92 \%$; b) neurological examination suggestive of intracranial hypertension with Cushing's triad (bradycardia, arterial hypertension and altered breathing pattern); c) cardiorespiratory auscultation showed no findings of interest, and abdominal examination with non-painful abdominal distension.

Complementary examinations: a) arterial blood gas (with non-rebreathing bag at $15 \mathrm{~L} / \mathrm{min}$ and $\mathrm{FiO}_{2}: 1$ ): hypoxemia and mixed acidosis: pH: 7.26, $\mathrm{PaO}_{2}: 82.6 \mathrm{mmHg} \mathrm{PaCO}_{2}: 50.0 \mathrm{mmHg}$, $\mathrm{HCO}_{3} 20,6 \mathrm{mmol} / \mathrm{L}$, oxygen saturation: $95.3 \%$; b) hemogram: leukocytes $7,86 \times 10^{9} / \mathrm{L}$, hemoglobin $13.20 \mathrm{~g} / \mathrm{dL}$, platelets $247 \times 10^{9} / \mathrm{L}$; c) blood chemistry: glucose $122 \mathrm{mg} / \mathrm{dL}$, urea $8 \mathrm{mg} /$ $\mathrm{dL}$, creatinine $0.44 \mathrm{mg} / \mathrm{dL}$, sodium $137 \mathrm{mmol} / \mathrm{L}$, potassium $3.4 \mathrm{mmol} / \mathrm{L}$, procalcitonin $<0.05 \mathrm{mg} /$ $\mathrm{mL}, \mathrm{C}$-reactive protein $1.24 \mathrm{mg} / \mathrm{dL}$; d) coagulation study: prothrombin activity: $56 \%$; fibrinogen $6 \mathrm{~g} / \mathrm{L}$ (normal values $2-4 \mathrm{~g} / \mathrm{L}$ ); e) microbiological studies: nasopharyngeal wash collection: PCR + coronavirus NL63; blood culture, urine culture, CSF culture: bacterial, virus herpes, enterovirus, parechovirus negative.

At the hospital admission, symptoms were compatible with intracranial hypertension, which was treated with an intravenous bolus of $3 \%$ 
hypertonic saline, and orotracheal intubation. A cranial computed tomography (CT) scan was performed, and no pathological findings were confirmed.

The patient evolved during his first 24 hours after been admitted in the Pediatric Intensive Care Unit to: a) neurological failure: encephalic involvement and lumbar puncture with cerebrospinal fluid (CSF) cytochemical and immunological study: glucose $110 \mathrm{mg} / \mathrm{dL}$; protein: $60 \mathrm{mg} / \mathrm{dl}$; cells: 13 leukocytes $/ \mathrm{mm}^{3}$; anti N-methyl aspartate receptor antibodies (anti NMDA) in cerebrospinal fluid and blood negative; anti myelin oligodendrocyte glycoprotein antibodies (anti MOG) and anti glycoprotein antibodies in aquaporin-4 (anti NMO): negative; b) cardiogenic shock with: acute pulmonary edema secondary to cardiac insufficiency in relation to myocarditis: 1.-Electrocardiogram: sinus tachycardia at 160 bpm; 2.-Echocardiography: mild systolic ventricular dysfunction, shortening fraction $20 \%$; 3.- Biochemical parameters of cardiac muscle involvement: high sensibility troponin: $2966 \mathrm{pg} / \mathrm{ml}$, and natriuretic pro-peptide B type (ProBNP): 31122 pg/ml; lactate: $2 \mathrm{mMol} / \mathrm{L}$ (normal values: $0.40-2.00 \mathrm{mmol} / \mathrm{L}$ ); c) Severe acute respiratory failure with ratio $\mathrm{PaO}_{2} / \mathrm{FiO}_{2}$ : $45 \mathrm{mmHg}, \mathrm{SaO}_{2}: 80 \%$, respiratory acidosis $(\mathrm{pH}$ : 7.09; $\mathrm{PaCO}_{2}: 80 \mathrm{mmHg}$ ) with radiological image of bilateral alveolar-interstitial affectation (Figure 1) and the need for a high mechanic respiratory support (pressure control modality; $\mathrm{FiO}_{2}$ : 1 ; peak pressure: $37 \mathrm{mmHg}$; PEEP:12 $\mathrm{cmH}_{2} \mathrm{O}$; plateau pressure: $30 \mathrm{cmH}_{2} \mathrm{O}$; driving pressure $18 \mathrm{cmH}_{2} \mathrm{O}$; static compliance: $4.1 \mathrm{ml} / \mathrm{cmH}_{2} \mathrm{O}$ ); d) Mild hematological failure with protombine activity $<60 \%$, intravenous vitamin $\mathrm{K}$ was administered (5 mg/12 h).

The patient was sedated-relaxed and ionotropic support containing dopamine $5 \mathrm{mcg} /$ $\mathrm{kg} / \mathrm{min}$, noradrenaline $0.1 \mathrm{mcg} / \mathrm{kg} / \mathrm{min}$ and levosimendan $0.2 \mathrm{mcg} / \mathrm{kg} / \mathrm{min}$. During the first 72 post-admission hours, it was observed a progressive improvement of the cardiac contractility, the gas exchange and the pulmonary involvement (Figure 1). The patient was extubated at his $7^{\text {th }}$ admission day, but tracheal reintubation was required after 12 hours because of respiratory failure secondary to predominant axial muscle weakness interpreted in relation to myopathy of the critically ill patient with respiratory secretions retention and ineffective cough.

A nuclear magnetic resonance imaging (MRI) was performed and it was objectified the following (Figure 2): a) spinal cord lesions consistent with demyelination in the context of acute encephalomyelitis b) extensive bulbar injury probably of inflammatory origin; c) partial repletion defect at the torcular herophili consistent with venous sinuses thrombosis.

Immunoglobulin intravenous perfusion was initiated (400 mg/ kg/ day for five days), together with intravenous methylprednisolone (30 mg/ $\mathrm{kg} /$ day) and anticoagulation with subcutaneous enoxaparin $(1 \mathrm{mg} / \mathrm{kg} / 12$ hours during his stay in ICU).

After serial medical examinations, it was constated a generalized muscle weakness, hypersalivation by altered deglutition and weak coughing. The patient was extubated two more times without success, and tracheostomy was

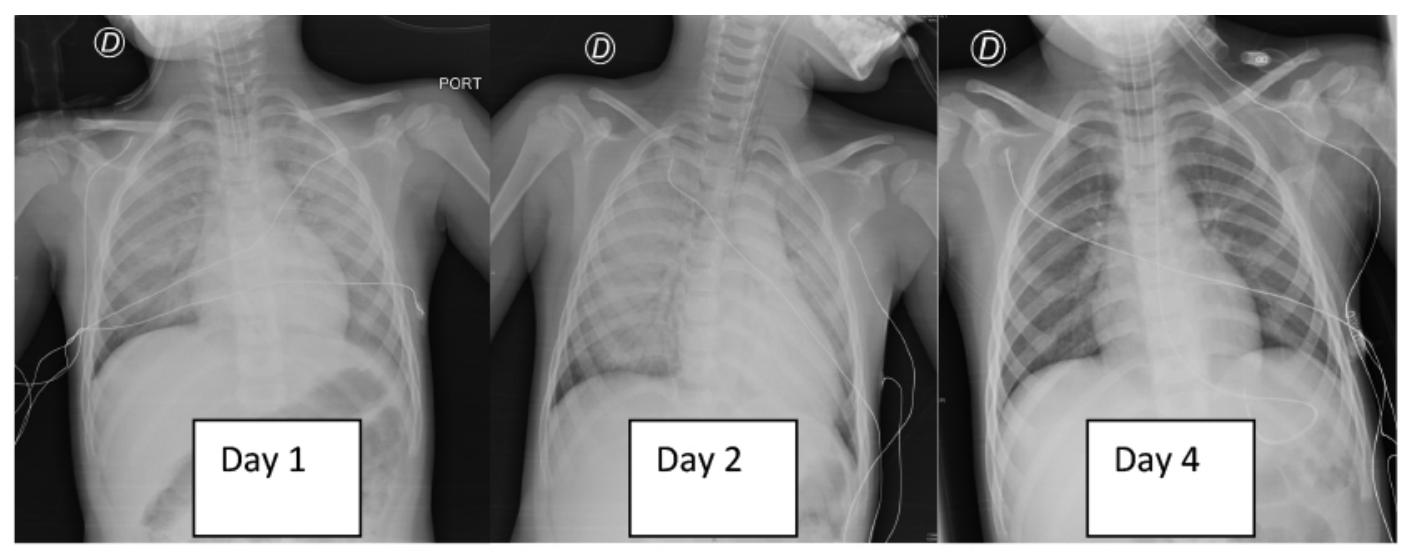


performed. Ten days later, the patient could be weaned from the mechanic ventilation, continuing with oxygen therapy. The patient was discharged from the Unit of Pediatric Intensive Medicine after 50 days presenting cardiorespiratory stability, generalized muscle weakness, motor incoordination, ataxia, and dysphagia which precise respiratory physiotherapy, muscle groups rehabilitation and nasogastric tube feeding.

Currently, 6 months after hospital discharge, the patient breathes spontaneously and presents the following neurological examination: good tone and trophism; fine distal tremor, slightly more marked dysmetria in the left upper limb; mild axial ataxia, increased lift area; gait with a slight equine tendency, no possibility of walking on heels and difficulty walking in tandem.

\section{DISCUSSION}

The clinical case presented can be considered as an uncommon presentation of a respiratory infection by CoV-NL63 since it includes extrapulmonary findings and its severity leads to a multiple-organ failure.

Coronaviruses $(\mathrm{CoV})$ are RNA viruses among which we can highlight: a) SARS-CoV-2 firstly identified in December 2019 in Wuhan (China), ${ }^{4}$ responsible for the current pandemic disease associated with the infection (COVID-19); b) Human CoV 229E (HCoV-229E) and human CoV OC43 (HCoV-OC43) causal agents of upper respiratory tract infections, the common cold included; ${ }^{5}$ c) Betacoronavirus: SARS-CoV as causal agent of the severe acute respiratory syndrome $^{6}$ and MERS-CoV as causal agent of a middle east respiratory syndrome; ${ }^{7}$ d) AlphaCoV: HCoV-NL63 causal agent of a common cold, conjunctivitis and fever in infants. ${ }^{8}$

The pulmonary involvement and the needs for high mechanic respiratory support orientated the clinical presentation towards the diagnosis of a global respiratory failure (hypoxemic and hypercapnic). ${ }^{9}$

Although the lung protective strategy was attempted in mechanical ventilation, the existence of a myocarditis with heart failure and the rapid resolution of the situation of cardio-respiratory instability in 72 hours, guided us owards a myocardial involvement by CoV-NL63, which triggered a secondary congestive respiratory failure, excluding the syndrome of acute respiratory distress based on the Berlin criteria, because there was a cardiogenic cause. ${ }^{9}$

The most commonly identifiable cause of myocarditis is the viral infection ${ }^{3}$ by direct cell injury and T-lymphocyte-mediated cytotoxicity. $7,8,10$ The MERS-CoV and SARS-CoV have cardiotropism. ${ }^{6,7}$

The patient was firstly diagnosed with "myopathy of the critically ill patient" in view of his need for prolonged mechanical ventilation, intravenous muscle relaxation and corticoids administration at high dose. Based on his muscle weakness, axial hypotonia and deglutition

FIGURE 2. MRI: spinal cord lesion consistent with acute disseminated encephalomyelitis (left). On the right, bulbar injury (white arrow) and venous sinuses thrombosis (red arrow) associated to CoV-NL63 infection
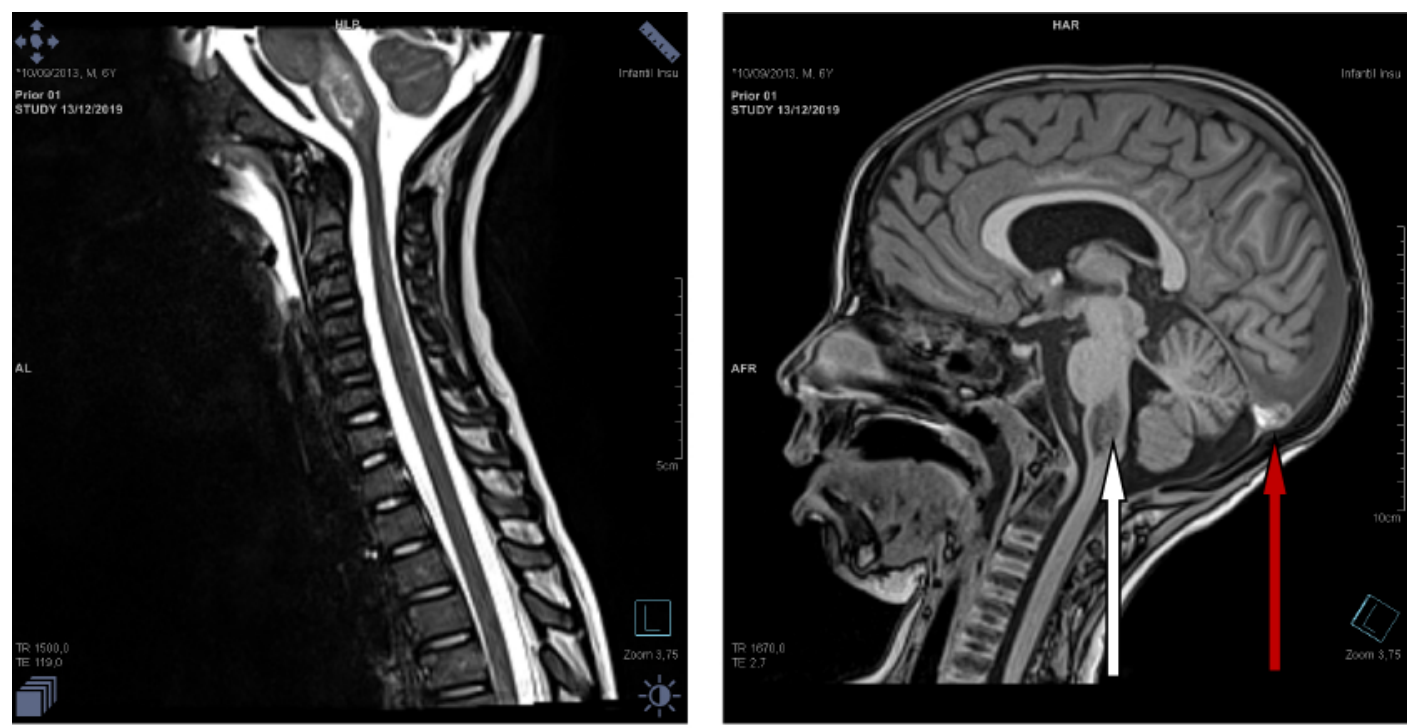
difficulty, an MRI was performed. The images of which evidenced: a) acute encephalomyelitis and a bulbar injury, both consistent with viral infection (cervical rhombencephalomyelitis of probable CoV-NL63 para-infectious origin). Neuroinvasion can also be produced through the olfactory pathway ${ }^{10-13}$ after an intranasal infection, as it has been reported in mice infected by $\mathrm{HCoV}$ OC43 and SARS-CoV; ${ }^{14}$ b) cerebral venous sinuses partial thrombosis, as described for the actual pandemic (COVID-19), in which procoagulant events are within the findings associated to this CoV. ${ }^{15}$

Muscle weakness, dysphagia and the incapability to maintain the respiratory tract in an effective manner (tracheostomy required) could be justified by alteration of the nuclei of lower motor (IX, X, XI, XII) and sensory (V, IX, X) cranial nerves, together with the corticobulbar and corticospinal tracts consistent with the bulbar injury evidenced by MRI.

To sum up, this clinical case is presented to highlight an uncommon clinical presentation caused by a non-COVID-19 CoV, but which shares some clinical signs of COVID-19 and shows a similar severity: myocardial and respiratory involvement, procoagulatory phenomena, and significant neurological sequelae, in a 5-year-old child where severe extrapulmonary involvement is exceptional.

\section{REFERENCES}

1. Charlton CL, Babady E, Ginocchio CC, Hatchette T, et al. Practical Guidance for Clinical Microbiology Laboratories: Viruses Causing Acute Respiratory Tract Infections. Clin Microbiol Rev. 2018; 32(1):e00042-18.

2. Desforges M, Le Coupanec A, Dubeau P, Bourgouin A, et al. Human Coronaviruses and Other Respiratory Viruses:
Underestimated Opportunistic Pathogens of the Central Nervous System? Viruses. 2019; 12(1):14.

3. Kociol RD, Cooper LT, Fang JC, Moslehi J, et al. Recognition and initial management of fulminant myocarditis: a scientific statement from the American Heart Association. Circulation. 2020; 141(6):e69-92.

4. Lu H, Stratton CW, Tang YW. Outbreak of pneumonia of unknown etiology in Wuhan China: the mystery and the miracle. J Med Virol. 2020; 92(4):401-2.

5. Masters PS, Perlman S. Coronaviridae. En: Knipe DM, Howley PM, (eds). Fields virology. 6th ed. Philadelphia: Wolters Kluwer; 2013.p.825-58.

6. Drosten C, Günther S, Preiser W, van der Werf S, et al. Identification of a novel coronavirus in patients with severe acute respiratory syndrome. $N$ Engl J Med. 2003; 348(20):1967-76.

7. Abdel-Moneim AS. Middle East respiratory syndrome coronavirus (MERS-CoV): evidence and speculations. Arch Virol. 2014; 159(7):1575-84.

8. van der Hoek L, Pyrc K, Jebbink MF, Vermeulen-Oost W, et al. Identification of a new human coronavirus. Nat Med. 2004; 10(4):368-73.

9. ARDS Definition Task Force; V Marco Ranieri, Gordon D Rubenfeld, B Taylor Thompson, et al. Acute respiratory distress syndrome: the Berlin Definition. JAMA. 2012; 307(23):2526-33.

10. Mesel-Lemoine M, Millet J, Vidalain PO, Law H, et al. A human coronavirus responsible for the common cold massively kills dendritic cells but not monocytes. J Virol. 2012; 86(14):7577-87

11. Dahm T, Rudolph H, Schwerk C, Schroten H, et al. Neuroinvasion and Inflammation in Viral Central Nervous System Infections. Mediators Inflamm. 2016; 2016:8562805.

12. Desforges M, Le Coupanec A, Stodola JK, Meessen-Pinard $\mathrm{M}$, et al. Human coronaviruses: Viral and cellular factors involved in neuroinvasiveness and neuropathogenesis. Virus Res. 2014; 194:145-58.

13. Durrant DM, Ghosh S, Klein RS. The Olfactory Bulb: An Immunosensory Effector Organ during Neurotropic Viral Infections. ACS Chem Neurosci. 2016; 7(4):464-9.

14. McCray PB Jr, Pewe L, Wohlford-Lenane C, Hickey M, et al. Lethal infection of K18-hACE2 mice infected with severe acute respiratory syndrome coronavirus. J Virol. 2007; 81(2):813-21.

15. Ehrenfeld M, Tincani A, Andreoli L, Cattalini M, et al. Covid-19 and autoimmunity. Autoimmun Rev. 2020; 19(8):102597. 